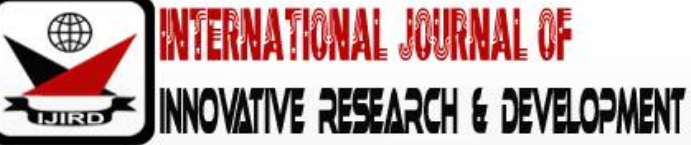

ISSN 2278 - 0211 (Online)

\section{Factors That Affect Strategic Planning Implementation in Diploma Teachers Colleges in Tanzania}

\begin{tabular}{|c|}
\hline Mollel Babu Meigaru \\
Ph.D. Student, Department of Policy and Planing, Mwenge Catholic University, Tanzania \\
Dr. Peter Siamoo \\
Lecturer, Department of Education, Mwenge Catholic University, Tanzania \\
Dr. Victorini Salema \\
Lecturer, Department of Education, Mwenge Catholic University, Tanzania \\
\hline
\end{tabular}

\begin{abstract}
:
The study has examined the factors that affect strategic planning implementation in Diploma Teachers Colleges in Tanzania. The study used mixed research methods, under concurrent triangulation design. The sample sizes of 10 colleges out of 35 public teachers Colleges with 110 respondents out of the entire population were selected for the research. The study sample comprised 10 College Principals/Vice Principals and 100 tutors. The study used three sampling techniques which were simple random sampling, stratified random sampling, and convenience sampling. Data were collected through interview guide, document analysis guide; observation and questionnaires and Quantitative data were analyzed through descriptive statistics and presented using frequency, distribution tables, and percentages. The qualitative data was summarized, coded and analyzed by the research questions. Pilot testing of the research instruments were conducted in one of the teachers' college where the targeted respondents were given a questionnaire and interview guide. The study identified internal and external factors that affected the success of strategy implementation which include resource availability, poor communication, fear of change, lack of skills among tutors and management in the formulation and implementation of the plan, lack of keen leadership and laziness.
\end{abstract}

Keywords: Strategic plan implementation, college performance

\section{Introduction}

Quality education of primary and secondary schools is dependent on quality teachers who depend on quality teachers training colleges. Despite that, colleges are service-oriented; the Government requires them to make a strategic plan to help succeed in their college activities (Medium Term Strategic Planning and Budgeting Manual, 2005).

A strategic plan in teachers colleges helps the academic achievement and income-generating projects and minimizes dependency of subsidy from the Central Government. It also helps to plan for the construction and renovation of college buildings (School Construction and Maintenance Strategy -SCMS 2019).

Although, the government introduced a strategic plan to Teachers Colleges for success and survival, visit inspection report for colleges conducted by quality assurance officers in June 2018 revealed that some colleges failed to prepare the strategic plan on time (Quality assurance inspection report for colleges, 2018). Incidentally, while some colleges that have strategic plans were performing better in terms of academic performance and income-generating projects, some colleges continued to have poor academic performance despite having a strategic plan.

An evaluation study done by the Ministry of Education in all teacher's colleges and visit inspection reports for colleges conducted by quality assurance officers in Northern Eastern Zone Lake and Eastern zone revealed that some colleges were missing an action plan, a very important document that put the strategic plan into action. (Quality assurance northern Eastern zone report 2018, Quality assurance Division in Lake Zone report 2018, \& MOEST Teachers Colleges Conditional Survey 2016).

Needs assessment conducted in year 2017 by Teacher Education Support Project in Seven Educational Zones with TCs in bracket, namely; Eastern Zone (Vikindu, Morogoro, Ilonga, Mhonda, Dakawa); Southern Zone (Mtwara, Mtwara Ufundi, Nachingwea, Kitangali, Songea); Southern Highlands (Klerruu, Tandala, Mpuguso, Tukuyu, Sumbawanga); Central Zone (Mpwapwa, Bustani, Kinampanda); Northern Zone (Korogwe, Marangu, Singachini, Mandaka, Patandi, Monduli, Mamire); lake Zone ( Butimba, Murutunguru, Tarime, Bunda, Katoke); Western Zone (Tabora, Ndala, Shinyanga, Kabanga, Kasulu) come out with the following major findings:

Results show that the supply of teaching and learning materials was the highest necessity reported by $75.8 \%$ of the 33 principals followed by infrastructure maintenance (45.5\%); professional development of teacher educators (39.4\%); equipping of both libraries and ICT labs respectively (39.4\%) and $(27.3 \%$ 
This called for a question of why these situations exist while strategic plan, which is mandatory to all colleges, normally addresses them. A best and well designed and implemented strategic plan is a good indicator of college's progress and development including student academic achievement, construction, and renovation of college buildings and development of income generation projects that reduce governmental financial dependency.

It was perceived that the extent to which each goal of the strategic plan was addressed could have implications on the realization of the expected college goals, that is, student-teachers academic performance, renovation and construction of new buildings and growth of income-generating projects.

None of the study assessed the factors that affect strategic planning implementation in diploma teachers' colleges in Tanzania that is why this study examined the factors that affect the implementation of strategic plan in the public diploma teachers' colleges in Tanzania.

\section{Review of Empirical Studies on Factors That Affect Strategic Planning Implementation}

There are many factors listed in the literature that influence strategic planning practices.

Odero (2016) carried out the study to examine communication as a factor affecting effective strategy implementation in the banking industry in Kakamega County, Kenya. The study adopted a descriptive survey research design. This research limited itself to four selected commercial banks in Kakamega County covering a sample of 25 respondents drawn from 85 employees of Kenya commercial bank, Equity Bank, Cooperative Bank, and National bank.

Stratified and simple random sampling techniques were used. The study relied on primary data which was obtained through a structured questionnaire. Data were analyzed using descriptive and inferential statistics. The result of this study reveals that a relationship exists between communication and strategy implementation in the banking industry in Kakamega County, Kenya. Odero, result cement the finding of the current study, though, the only difference was the context of the study. Communication in the current study was mentioned in Teacher College's context.

In the study of investigating factors influencing the effectiveness of strategic planning processes among local NGOs in Malawi, Kambewa (2007) employing qualitative methods. The study used the levels of complexity' and 'stages of organization development' models to analyze factors influencing the strategic planning process and the roles and responsibilities played by the board, management, donors, consultants, and communities respectively in five selected local NGOs. The study revealed that the level of implementation of the strategic plan was low (46\%). In comparison, the implementation was lower for organizational capacity building activities as compared to project activities. HIV and AIDS NGOs had higher levels of implementation as compared to their human rights counterparts. The major causes of the low implementation were the local NGOs' inadequate financial independence from donors to respond effectively and autonomously to the needs and priorities of their beneficiaries; and inadequate capacity for the boards, management, donors, consultants, and communities to effectively go through the strategic planning process.

Kambewa research stated well the purpose of the study, agreed with the title and problem. The author's objectives were attainable and included enough information. The researcher design was adequate and the data gathering procedures were explained. Moreover, factors that affect strategic planning practices in teachers Colleges which is the learning institutions have not been clarified since the study investigates factors influencing the effectiveness of strategic planning processes among local NGOs in Malawi.

Mwai, Namada \& Kamau (2018) researched the Influence of Manager Personality on Strategy Implementation in Private Universities in Kenya. The purpose of his paper is to investigate the influence of manager personality on strategy implementation in private universities in Kenya. Data was collected from 360 top, middle-level managers and lecturers in 23 private universities in Kenya. The hypothesis was tested using structural equation modeling (SEM), path analysis. The study revealed that manager personality has a positive and significant influence on the strategy implementation of private universities in Kenya. Mwai study has added knowledge about the manager personality on the implementation of strategies through the tools used to measure manager personality are complex.

Mucai (2014) carried out an analysis of factors influencing the implementation of the strategic plan in selected tertiary institutions in Meru Central District in Kenya. The research design was a descriptive survey, using a stratified random sampling design; a quota of $33 \%$ was established for each of the strata in each institute from the three stratus of top management, heads of departments and lectures. A table of random numbers was used to select a sample of 60 individual respondents for the study. The study used a structured questionnaire as the data collection instrument both descriptive and inferential statistical analysis techniques were used to test the four Hypotheses of the study.

The study concludes that the weak influence of managerial behavior was as a result of strategic thinking of the management and the influence of rewards and incentives were found to be weak as it was the intrinsic motivation of the teacher's professional ethics than extrinsic motivation by management through tangible reward by Management that made the lecturers co-operate in the implementation of strategic plan. Institutional policies were revealed to be weak in influencing strategy implementation because of low awareness and the infrequent use of the service charter which is a critical 'barometer' of strategy implementation effectiveness and efficiency.

The target population in Mucai studies was identified however the sample size was inadequate compared to the research design used even if an in-depth interview was conducted. The research design was identified and the data gathering instrument has been described and appropriate. Conclusion and implications were formulated with the knowledge that Institutional policies were revealed to be weak in influencing strategy implementation. The conclusions were based on the finding and logically stated. Mucai study does not, however, explain the extent to which each of the factors affects organizational performance. Equally, this study was conducted in Kenya which is a different context from Tanzania, therefore, this study assessed the effectiveness of implementation of strategic plan in teachers colleges. 
Ndegwah (2014) carried out the study on the factors affecting the Implementation of Strategic Plan in Public Secondary Schools in Nyeri County, Kenya. The study was guided by four objectives and data was collected to answer the following four questions: - How Managerial skills, Institutional policies, Resources allocation, Rewards, and Incentives influence the implementation of Strategic Plan.

The population for the study was the institutions' Principals or their Deputies in the 2 Sub-counties. The accessible population was made up of 66 schools' Principals/ Deputies (32 in Mukurweini and 34 in Othaya) and an interviewer-administered questionnaire was used. Both descriptive and quantitative was collected and analyzed to answer the four questions of the study. The study had 20 school's responding from each sub-county representing $65 \%$ in Mukurweini and $60 \%$ in Othaya.

Based on the findings, it can be concluded that public secondary schools in Mukurweini \& Othaya Sub-counties had a strategic plan and their implementations are influenced by other factors, Managerial skills, Institutional policies, Resource allocation, and Rewards/Incentives. It's recommended that Principals/Deputies be equipment with the necessary Managerial Skills; schools should enforce institutional policies; they should have resources allocation policies/ budgets and should have reward/incentive schemes which help in the successful implementation of the school's strategic plan.

Othaya recommendation of equipping Principals/Deputies with the necessary Managerial Skills; resources allocation policies/ budgets and provision of reward/ incentive schemes which help in the successful implementation of the school's strategic plan gives some clues on the areas of in-service of tutor and management to the current study.

Anyieni (2016) undertook a study on the Assessment of the Factors Influencing the Implementation of Strategic Plan in Secondary Schools in Kenya a case study of public Secondary Schools in Kenya. The specific objectives were to analyze the effects of leadership style and communication in the successful implementation of the strategic plan. A descriptive survey design using stratified sampling was used. Primary data was collected through questionnaires that were administered through the 'drop and pick later' method while secondary data was gathered from the relevant Ministry of Education, Teachers Service Commission (TSC) and Government of Kenya publications like the Strategic plan. Quantitative data were analyzed through descriptive statistics and multiple regression analysis. Quantitative data was presented using bar graphs, pie charts, and frequency distribution tables.

The findings confirmed that various management styles are favored by organizations for their effective implementation of the strategic plan. Leadership styles exist in organizations for the effective implementation of the strategic plan. The study findings imply that most public secondary schools could be having problems with strategic plan Implementation due to a lack of multidirectional communication flow. The purpose of the study was to analyze the effects of leadership and communication in successful implementation of a strategic plan without considering another factor. This study examined deeply implementation of the strategic plan in influencing three key areas which are the academic performance, income project generating projects and infrastructure in Teachers Colleges.

Alice (2013) undertook a study to investigate the factors affecting the implementation of a strategic plan in Kenya. A descriptive survey of 258 NGOs was conducted from a population frame of 2588 NGOs operating in Nairobi District under the Youth, Relief, Micro-Finance, Welfare and Health sectors. Statistical inferences using 2-way ANOVA indicated that a high reliability was achieved by the data collection instrument with Cronbach's alpha coefficients ranging from 0.801 to 0.875 . Both tests of significance using ordinary least squares regression and correlation analysis indicated a strong significance amongst the variables as well as when combined against the dependent variable. Management styles, organization culture, stakeholders and organization resources had a great significance on strategic plan implementation while communication had some significance but not as strong as the other variables. This enabled a conclusion to be made that management style, communication, organizational culture, stakeholders and organizational resources all affect the effectiveness of the implementation of the strategic plan.

Alice's research tables were well organized but, due to the difficulty of the statistical test employed, would not stand alone to the average reader. The conclusion was based on the findings and logically stated. However, Alice (2013) looks at strategy implementation with the notion of a business organization only and market in mind Alice (2013) generalizes the reasons for strategy failure as well as how to avoid the pitfalls. However, this might not be the case in reality. Although some of the reasons he gives for strategy failure may apply in the public sector, much of the public sector's operating environment and goals have not been captured in his study. This study looked at strategy implementation in Teacher Colleges. This explored specific issues that are only found in this sector that otherwise could not have been highlighted.

\section{Summary of Literature Review and Statement of Knowledge Gap}

Despite these findings reported, few studies were conducted in Tanzania concerning factors that affect strategic planning implementation in diploma teachers colleges in Tanzania. Moreover, most of the studies reviewed used only one research method which was either a qualitative research method or quantitative method. Nevertheless, there was no study conducted which had examined factors that affect strategic planning implementation in diploma teachers colleges in Tanzania. Likewise, many studies reviewed failed to use more than two instruments for data collection and concurrent triangulation research design which intend to bring the differing strength of qualitative and quantitative methods. Therefore this study used concurrent research design to examine factors that affect strategic planning implementation in diploma teachers colleges in Tanzania, 


\section{Research Methodology}

\subsection{Research Design}

The study used a mixed-method under concurrent triangulation design where the researcher collected and analyzed qualitative and quantitative data on the same phenomenon. In the concurrent design, both qualitative and quantitative data are collected in a single phase with the general aim of obtaining a more developed understanding of the phenomenon under study. The data can be collected from the same participants or similar target populations. The goal is to get different but complementary data that validate the overall results. Triangulation refers to the use of multiple methods or data sources in research to develop a comprehensive understanding of phenomena (Carter, 2014). Both qualitative and quantitative data were collected in response to research questions. The intention of using this design was to bring together the differing strengths and non-overlapping weaknesses of quantitative methods, large sample size, trends, generalization with those of qualitative methods, (small sample size, details, in-depth (Creswell, 2013).

\subsection{Target Population}

The target population in this study was 35 public teachers Colleges in Tanzania and respondents comprised 35 College Principals/ Vice Principals and 1, 263 tutors. College Principal/Vice-Principals was included in the study because they were responsible to provide guidance and supervision during the strategic plan process, formulation, implementation, monitoring, and evaluation. Other people participated in the study because of their key role in strategic plan implementation including the academic dean, dean of students and registrars. Academic head, dean of students and registrars are responsible and accountable for setting and advancing the strategy of their Department in line with college strategic plan and direction while tutors are key implementers of strategic plan goals.

\subsection{Description of Sample and Sampling Procedure.}

In this study, the sample consisted of 10 diploma teachers' colleges, 10 principal/ vice principal, 35 departmental leaders, and 100 college tutors. The study adopted simple random, stratified and convenience sampling to select the respondents. Other respondents were automatically included in the study.

\subsubsection{Sampling of Colleges}

The study involved 10 Diploma public teachers' colleges out of 35 colleges in Tanzania. Stratified sampling was used to separate colleges into subgroups or strata according to zones (Inspectorate zones), from each of the zonal subgroups created Colleges offering Diploma. The researcher categorized diploma colleges into six inspectorates' zone with diploma teachers' colleges which were southern lake zone, Western zone, Northern highland, North Eastern, Northwestern and Southern highland zone. The lottery method of creating a simple random sample was taken from each stratum end up with 10 diploma teacher colleges.

\subsubsection{A Sampling of College Principal/ Vice Principals}

College Principal/ Vice-Principal was automatically included in the study because there was only one person in each position. The researcher chose top management because they were responsible for influencing the path taken to accomplish a laid goals by defining the positions and task roles, removing obstacles to performance, by enlisting the assistance of group members in setting goals, promoting group cohesiveness and team effort, by increasing the opportunities for personal satisfaction in work performance and by reducing stress and external controls.

\subsubsection{A Sampling of College Tutors}

Convenience sampling (also known as availability sampling) was used to select college tutors due to the availability of each tutor to participate in the study at that specific time. Convenience sampling is a specific type of nonprobability sampling method that relies on data collection from population members who are conveniently available to participate in the study. In other words, this sampling method involves getting participants wherever you can find them and typically wherever is convenient.

Description of sample was summarized in the table 4.1:

\begin{tabular}{|c|c|c|c|c|}
\hline Target Population & Total Number & Sample Size & Percentage & Sampling Procedure \\
\hline $\begin{array}{c}\text { Principal/Vice } \\
\text { Principals }\end{array}$ & 35 & 10 & $29 \%$ & Automatic \\
\hline Tutors & 1,263 & 100 & $7.9 \%$ & convenience sampling \\
\hline Colleges & 35 & 10 & $29 \%$ & Stratified sampling \\
\hline
\end{tabular}

Table 1: Summary of Sample and Sampling Procedure

\subsection{Description of Data Collection Instruments}

An instrument is a technique or method of data collection. Data collection instruments refer to devices used to collect data such as questionnaires, tests, structured interview schedules and checklists (Kok, 2013). This study employed varieties of instruments to facilitate the collection of data. The instruments that were used included: interview guide, questionnaire, observation guide, and document analysis guide. 


\subsubsection{Questionnaire for Tutors}

Tutors Questionnaire had two sections which were demographic information of the respondents and the second section aim at collecting quantitative information about research questions. Questionnaires were administered to 10 tutors in each college which make a total of 100 respondents. This helped to gather quantitative information concerning the implementation of strategic planning in influencing organizational performance.

\subsubsection{Interview Guide for College Principals and Vice-Principals}

The interview guide was administered to college principals/ vice-principals to collect information about research questions. The Interview guide for Principal had questions that addressed research questions on the implementation of the strategic plan since the Vice Principal is the supervisor and implementer of the college duties and activities Some of the details needed by the researcher include extent to which organizational leaders were committed to provide directives to support the implementation of strategic initiatives and how far the management motivated to maintain and support the implementation of strategic initiatives. More ever, college principal was asked on the effectiveness of strategic plan in improving academics performance, income-generating projects and infrastructure in Public Teachers Colleges in Tanzania; factors that affect strategic planning implementation in Public Teachers Colleges in Tanzania; and possible ways to address challenges in the implementation of the strategic plan.

\subsection{Pilot Testing of Research Instruments}

The subject to be in the pilot testing was similar to those targeted in the actual study. Therefore, employees working in one of the public diploma teacher colleges were contacted to participate in the pilot testing. The pilot testing data were collected using questionnaires and interview guides from 3 departmental leaders, College Principal/VicePrincipal using the same procedures of data collection for respective respondents. The result of pilot testing had helped to find out whether everyone in a sample not only understands the questions, but understands them in the same way. The college that was used for the pilot study was not included in the sample during the actual study.

\subsection{Validity of the Research Instrument}

Validity is the extent to which the instruments used during the study measure the issues which were intended to be measured (Amin, 2005; Joppe, 2000). Content validity was employed in this study. To obtain content validity, this study evaluated the research instrument with experts in one of the public universities and one of the research institutions by conducting interviews, asking them to give their comments on the instrument. Questionnaire and interview questions were distributed to experts. The experts then commented on the questionnaire and interview guide. This helped to identify ambiguous questions in the instruments and be able to re-align them and ensure that the statements were clearly stated in a way that readers can have the proper interpretation of questions intended by the researcher.

\subsection{Reliability of the Research Instrument}

The reliability of the questionnaire's questions was done through Cronbach's alpha reliability coefficient which enabled the researcher to check for internal consistency of the instruments. In assessing reliability through Cronbach's alpha, authors suggest different levels of acceptance.

Nunnally (1994) recommends that an acceptable alpha is between .50 and .60. Panayiotis (2013) increased the level of acceptance and considered that the alpha should exceed the minimum of .70 for internal consistency. While different views have been recommended about levels of acceptance, it is generally agreed that an alpha of .70 and over is acceptable. The calculated value of the reliability coefficient of the scale items through SPSS was 0.903 for this study. Qualitative research instruments were ensured through member checking which helped to seek an opinion as to how questions were made easier to understand. The researcher had given questions to the members to seek opinions as to how questions could be made easier to understand and determine accuracy.

\subsection{Description of the Data Collection Procedure}

The researcher followed all the necessary processes to make sure the government managerial organs were well informed about the data collection. The researcher obtained an introduction letter from MWECAU Postgraduate Director and submitted it to the Permanent Secretary, Ministry of Education, Science and Technology to request the research permit. The research permit from the Permanent Secretary was submitted to College Principals for them to inform the department leaders and tutors who were the respondents of the study instruments. The researcher distributed questionnaires to 30 departmental leaders and interviewed Principals/Vice-principal by asking structured questions and receiving the answers. The researcher wrote the responses at the time of the interview.

The researcher reviewed existing documents which were the strategic plan document, action plan, and college development plan documents. Reviewing of existing documents helped the researcher understood the history, and uses of the strategic plan with comparison to the organization operation. The review of the strategic plan and other related documents revealed a difference between formal statements of the plan and the actual strategic plan implementation.

\subsection{Description of the Data Analysis Procedure}

Data screenings were performed to make sure that the data collected can be depended on and were not led to misleading results. The data that was collected from the field using the questionnaires were screened, edited for accuracy, consistency, and completeness. Coding was used to assign a number to each answer thus allowing the transference of data 
from the questionnaire to Statistical Package for Social Sciences (SPSS). To analyze the quantitative data gathered from the questionnaires, SPSS version 20 was used. This technique was used to screen the data in terms of coding the data, dealing with missing data, analysis of non-response bias, as well as reliability and validity measurements. SPSS was employed to conduct preliminary data analysis and summarized in frequencies, mean, percentages and frequency distribution. Qualitative data analysis involved the identification, examination, and interpretation of patterns and themes in textual data and determined how these patterns and themes helped to answer the research questions at hand.

Qualitative data were analyzed by starting with the process of preparing and organizing raw data into meaningful units of analysis by clustering raw data into units that shared similar meanings or qualities. Responses were compared and summarized according to the research questions. Furthermore, Responses were coded, and clustered in similar theme categories, to produce meaning. The initial coding helped the researcher identify topics that appeared repeatedly. Narrations emerging from those clusters were interpreted to answer research questions.

\subsection{Ethical Consideration in Research}

The research was conducted by observing all necessary research rules, regulations, and responsibilities during the preparation and conduction of research in the field. The attention was paid to obtaining a research clearance letter from MWECAU authority, informing the permission of data collection to respondents.

Voluntary participation of respondents in the research was considered and respect for the dignity of research respondents was prioritized. Nevertheless, full permission was obtained from the participants before the study. Respondents participated based on informed consent. The protection of the privacy of research participants was ensured and adequate level of confidentiality of the research data was ensured. Communication about the research was done with honesty and transparency. However, the type of misleading information, as well as the representation of primary data findings in a biased way was avoided.

\section{Findings}

\subsection{Factors That Affect Strategic Planning Implementation in Teachers Colleges}

The researcher wanted to know the factors that affect strategic plan implementation in teachers' colleges. The finding collected through the questionnaire to tutors and interview guides to Principals indicated that several factors affect strategic plan implementation.

Results on the factors that affect strategic planning implementation in Teachers Colleges were presented on Table 2.

\begin{tabular}{|l|c|c|c|c|c|c|c|c|c|c|c|}
\hline & & \multicolumn{2}{|c|}{ SD } & \multicolumn{2}{|c|}{ D } & \multicolumn{2}{|c|}{ N } & \multicolumn{3}{|c|}{ A } & \multicolumn{2}{|c|}{ SA } \\
\hline i. & $\begin{array}{c}\text { G } \\
\text { Good communication has a } \\
\text { positive effect on strategic plan } \\
\text { implementation in my College. }\end{array}$ & 4 & 4.9 & 4 & 4.9 & 14 & 17.3 & 38 & 46.9 & 20 & 24.7 \\
\hline i. & $\begin{array}{c}\text { Strategic plan has enabled the } \\
\text { College to use effectively } \\
\text { organization resources. }\end{array}$ & 2 & 2.5 & 4 & 4.9 & 14 & 17.3 & 45 & 55.6 & 16 & 19.8 \\
\hline
\end{tabular}

Table 2: Factors That Affect Strategic Planning Implementation in Teachers Colleges

Source: Research Data 2019

\subsubsection{Communication during the Implementation of Strategic Plan Implementation}

The objective of this statement was to determine how effective communication has influenced strategic plan implementation in Teachers Colleges in Tanzania. The researcher sought to establish the respondent's opinion on whether good communication influence positively implementation of the strategic plan in public teachers colleges.

Table 2 shows that $46.9 \%$ of the respondents agreed and $20 \%$ strongly agreed that good communication had influenced strategic plan implementation in their College and $4 \%$ strongly disagree. These findings imply that the majority of the tutors affirm that good communication had influenced positively strategic plan implementation and it plays a major role in the implementation of strategic planning. It is, therefore, the responsibility of every college to ensure that communication is maintained to facilitate the effective implementation of the college plan.

When questions were posed to Principals through an interview on what were challenges in the implementation of the strategic plan, the Principals states that many challenges hinder the implementation of the strategic plan and these were challenges mentioned.

"Poor consultation between the College management and the Ministry of education Science and Technology were there was no communication during the formulation and implementation of strategic plan" (Interview for Principal, 26th March 2019).

Insisting on communication barrier, Principals said:

"The Ministry each year states the type of program to be offered and the infrastructure to be established according to the national priorities without considering college plan" (Interview for Principal, 29th March 2019).

Principal's response implies that there was a communication barrier between the Ministry of education science and technology and teachers' colleges in setting and implementing a strategic plan. Communication between the Ministry and teachers colleges helps in two main areas. The first area will help to identify the Ministry plans for specific college thus enabling the college to develop a strategic plan according to the college strategic plan. The Ministry will also be able to 
identify the specific needs of the college and redirect resources directly. The two-way communication helps to bring about good relationships and the implementation of a strategic plan without having the duplication of resources.

Nevertheless, the result from the Principals through probing questions during the interview, show that strategic plan implementation is poorly communicated among staff members therefore; the plan is poorly implemented in teachers colleges. Communication Creates Engagement. The importance of communication sometimes is overlooked or underestimated during the implementation of a strategic plan. Effective communication ensures that all members of the organization are aware of the plan, its importance and how they might be impacted.

Principal's responses concur with Sull, Homkes \& Sull (2015), who noted that communication to the organization and external stakeholders is crucial to the success of any strategic plan. When the strategic plan was developed and during its execution, it must be extensively communicated to the rest of the organization and relevant external stakeholders. Organizational members cannot execute a strategy if they do not know what the strategy is all about.

Moreover, Lewis (2019) affirms that effective communication is critical for successful strategic implementation of any plan, whether an organizational strategic plan or a marketing or operational plan. Those required supporting the plan need to be informed of the plan and its importance to the organization. Also, all employees should know why the plan was developed, what it means to the company, who will be involved in its implementation and how they can contribute to its success.

Nevertheless, Mutisya (2016) in his study on the influence of communication on strategy implementation among pharmaceutical companies in Nairobi Kenya concurs with the result when his study concluded that communication influences the strategic plan implementation greatly through short message service, internal memos, emails, stakeholder meeting, oral presentations and periodic reports that was used widely.

Thus, good communication within an organization is a prerequisite to business growth and is pivotal to ensuring a smooth and effective process flow led to greater productivity and profitability. From the mentioned studies, the strategic plan needs to be extensively communicated during its formulation and execution to the rest of the organization and relevant external stakeholders. Colleges should, therefore, adopt communication media which plays an important role in training, knowledge dissemination and learning during the process of strategy implementation.

\subsubsection{Strategic Plan and Organizational Resources}

The researcher further required the respondents to indicate to what extent the strategic plan had enabled the College to use effectively organization resources. The results from table 4.6 indicated that $55.6 \%$ agreed and $19.8 \%$ strongly agreed that, strategic plan have enabled the College to use effectively organization resources. Only $4.9 \%$ disagreed and 3.5 strongly disagreed that the strategic plan has enabled the College to use effectively organization resources.

The majority of the tutors agreed that the strategic plan has enabled the College to use effectively organization resources. Barney (2015) defines firm resources as: "all assets, capabilities, organizational processes, firm attributes, information, knowledge, etc. controlled by a firm that enables the firm to conceive of and implement strategies that improve its efficiency and effectiveness. Tutors, views concur with Brian (2019) who noted that, the planning process provides the information to the top management which is needed to make effective decisions about how to allocate the resources in a way that will enable the organization to reach its objectives. Productivity is maximized and resources are not wasted on projects with little chance of success. However, Lack of resources for proper implementation is another challenging factor for strategic plan implementation. Barney (2015) specified that, through strategic planning, resources are concentrated on a limited number of objectives by ensures that the most-effective use is made of the organization's resources by focusing the resources on key priorities thereby helping an organization to focus its efforts, to ensure that its members are working toward the same goals, and to assess and adjust its direction in response to a changing environment.

The Resources based theory which had guided this study supported the view that if the resource is valuable then it can act as a source of competitive advantage for the organization. Teachers colleges should identify the type and kind of resources found in the college and how those resources are effectively utilized to fulfill the goals of the strategic plan. Human resource Management through their skills and knowledge had also a considerable influence on the implementation of strategic plan and contribution in achieving competitive advantage. Employees who are well managed have a positive impact on college performance.

When principals were asked probing questions during the interview about the Strengths and opportunities, threat and weakness within and around their colleges to help them to reap the resources around them, one of the Principal said

"College community is supposed to think out of the box and utilize resources around them. There are opportunities around all colleges which need the college communities to discover and utilize it effectively" (Interview for Principal, 29th March 2019).

Knowing Strength, Weakness, Opportunities, and Threat within and out of the college environment enables colleges to build upon their strengths; avail opportunities to avoid threats and overcome weaknesses. SWOT analysis is crucial for evaluating the current status of the colleges in term of opportunities around them and for future planning.

The Principal's idea concurs with Abdel (2018) who explain that SWOT analysis evaluates the internal strengths and weaknesses, and the external opportunities and threats in an organization's environment. The internal analysis identifies resources, capabilities, core competencies and competitive advantages, using a functional approach to review finance, management, infrastructure, procurement, production, distribution, marketing, reputational factors, and innovation. The internal analysis is critical in identifying the source of competitive advantage. It pinpoints the resources that need to be developed to remain competitive. The external analysis identifies market opportunities and threats by looking at the competitors' environment, the industry environment, and the general environment. 
The observation done by the researcher during the normal routine of his work confirmed that all public teachers' colleges were strategically located in different geographical environments with a lot of opportunities around them. One of the colleges visited by the researcher was surrounded by two rivers on both side but the water is not utilized for agricultural activities while the institution adjacent to the college uses the opportunity for agriculture and livestock keeping.

There is no doubt that, for teachers colleges to remain stable and productive, effort should be made to identify what constitutes their strength, weakness, opportunities, and threat. It is the identification and careful analysis that would keep the successful implementation of the strategic plan. If teachers colleges do not make the necessary effort to identify their strengths, weakness, opportunities, and threat, such colleges are bound to fail in many areas and will not be stable.

Brunsson (2018), noted that to be successful means knowing how to use your resources to the best advantage, and it's very difficult to "win" if you haven't determined your strategy, one must understand fully the internal and external environmental factors that affect organization. With that understanding, colleges can identify clear advantages and use these to be successful. From there, it can make informed choices and implement the strategic plan effectively. The Strategic planning document provides the information to the top management on what is to be done and what kinds of resources are needed and how to allocate the resources in a way that will enable the organization to reach its objective.

\subsubsection{Lack of Skills in The Formulation and Implementation of the Strategic Plan.}

Ochola (2016), explains the type of skills needed for the successful implementation of a strategic plan by introducing, technical, leadership and conceptual skills. Lack of technical skills involves a lack of understanding of how the strategies should be implemented; customers and staff not fully appreciating the strategy; unclear individual responsibilities in the change process; difficulties and obstacles not acknowledged, recognized or acted upon; and ignoring the day-to-day business imperatives. The second skill includes leadership Skills where most empirical evidence suggests that firms with better-educated managers are more efficient and tend to grow more quickly. Conceptual Skills are the third skills mention by Ochola and indicated that there were difficulties to guess the commitment, time, emotion, and energy needed to translate the plan into action.

Elaborating on the lack of skills during the interview, Principals had this to say:

"People working in strategic planning need to be skilled in how to formulate and implement a strategic plan and able to analyze and evaluate a plan. Only through an analytical eye can strategic planners decide what steps a company needs to take" (Interview for Principal, 28th March 2019).

Describing the issue of lack of skills in the formulation and implementation of strategic plan one of the principal had this to say:

"Lack of skills among the tutor and management in the formulation and implementation of the strategic plan is one of the delay factors of the implementation of the strategic plan. Many staff members are not aware of how to prepare and implement the strategic plan. In some instances, only the principal has the skill to engage with strategic planning" (Interview for Principal, 28th March 2019).

The study established that there was a lack of technical, leadership and conceptual skills in the implementation of the strategic plan in teacher colleges. If stakeholders would have not the ability to engage in strategic planning formulation and implementation, the effect on the success of the institution would be at risk. The formulation and implementation of a strategic plan should be a team effort that can lead an organization to the path of success. Bryson (2018) declare that, executing strategy in today's business environment requires a learning mindset, both from individuals and the organization at large. By conducting "lessons learning" (rather than "lessons learned"), we can diagnose and solve problems throughout the entire project life cycle, rather than only at the end.

\subsubsection{Lack of Commitments and Willingness of the Staff Members}

The success or failure of an organization is closely related to employees' commitment towards their job or career. The level to which an employee engages in his or her work (job involvement), commits to and believes in the organization's goals and purpose (organizational commitment), desires to work (work ethic), and commits to a specific career or profession can all have an impact on an organization crucial competitive advantages - including higher productivity and lower employee turnover (Jiang \& Johnson, 2018).

Commenting on the Lack of commitments and willingness of the staff members, Principals had this to say;

"There was the unwillingness of some of the staff members from the college to be part of the process, both at the formulation and implementation stages. Many staff members see the strategic plan as an extra burden over and above their normal workload" (Interview for Principal, 26th March, 2019).

Another principal said:

"Lack of commitments, laziness, and irresponsibility among teaching and non-teaching staff was a challenge in the implementation of the strategic plan" (Interview for Principal, 28th March 2019).

The study revealed that there was a lack of some of the staff commitment in performing their roles which led to the poor performance of strategic plan implementation. This could be the reason for many teacher colleges to lack Sustainable academic performance, growth of income-generating project and construction of the building.

Khan, (2016) describe that; lack of employee commitment is the main threat for the survival of the organization as a loss of competent employee is a loss of competitive advantage for the organization. Employees who are committed to their organization and engaged in their work are vital for the company as they provide crucial competitive advantages which result in a higher production rate and lowers employee turnover rate. For that reason, the college management needs to understand the importance of building employee commitment and its impact on organizational performance. 
Nwachukwu (2018) study results show that employee commitment to strategy implementation has a positive and significant relationship with employee satisfaction. The more committed employees are to their firm's strategy implementation, the higher their level of satisfaction with their firms. Thus, employee commitment to strategy implementation has a positive impact on employee satisfaction.

\subsubsection{Fear of Failure and Changes}

Fear of failure is a significant obstacle that stands between a person and a goals. Fear of failure is the intense worry a personal experience when she/ he imagines all the horrible things that could happen if he/ she failed to achieve a goal (Wood, 2017).

One of the Principal said: Sometimes tutors, as well as non-teaching staff, were fearful of failure and changes believing that a change is something to be feared and avoided. Many Principals and teachers were so entrenched in their normal day-to-day activities that they do not want to engage in new endeavors. They want to stay with what is known to them and therefore do not support strategic planning. They fear that they will not achieve what was planned and will seem like a failure (Interview, 1st April 2019). Fear of failure and fear of change is something that happens to all human beings. But a human being who is determined to be successful must try and seek change at any cost. Teacher's colleges whose leaders persuaded staff to embrace change by adopting a strategic plan have proven to be more successful than those who have feared and failed to.

Moreover, the Principal's explanations concur with (Mih, 2016) who cement that, failure fearers tend to be anxious, high in self-doubt, and are uncertain about their ability to avoid failure or achieve success. Often in response to this fear of failure, Failure fearers may actively sabotage their chances of success (e.g., procrastinate, leave tasks until the last minute, or expend little effort) so that they have an excuse if they do not do so well. This excuse serves a protective function in that they can blame their poor performance on their procrastination, rather than a possible lack of ability

\subsubsection{Poor Cooperation among Leaders and Staff Members}

Aristotle defined man to be a social animal by nature. He cannot survive without working with others toward a common aim. The prime reason to cooperate in a working environment is to achieve organizational goals. Achieving this is only possible when the management allows staff members to work their best at their level Ferns (2018).

When one of the tutors was asked on the challenges in the implementation of the strategic plan, had this to say:

"No direct cooperation among leaders and staff members during the formulation and implementation of strategic plans and this is the reason to the failure of strategic plan implementation (Interview for a tutor, 1st April 2019).

Cooperation is a partner in the strategic process and implementation. In the absence of cooperation is competition. Cooperation in teacher colleges includes partnering with others in terms of resources, capabilities, and competencies in pursuit of mutual interests for the advancement of goals. This combination of efforts is beneficial and very fundamental to success.

To ensure success during the implementation of strategic plan teachers college members should be organized to ensure the overall strategic objectives were achieved and each individual should contribute. All departments had to be cooperated to ensure they worked together to achieve organizational aims. Through cooperation and coordination, college management should make sure that all workers and departments know what they need to achieve and when

Kaufman (2016) comment that, cooperation is important because it allows people and groups to work together to achieve a common goal or derive mutual benefits. It reduces unproductive competition and encourages employees to work together for the benefit of the organization. It reduces the desire of employees to compete against each other, which often is never good for the business and instead focuses on working together to achieve a common goal.

In general, the finding had revealed six factors that had affected strategic plan implementation which was, resource availability, communication, fear of change, Lack of skills among the tutor and management in the formulation and implementation of the plan, leadership and laziness. Further, resource availability was ascertained to be the most influential factor, followed by a lack of skills, then by communication. Teachers' college management should understand that in a cooperation-rich workplace, individuals voluntarily engage in open communication. In the atmosphere of cooperation, workers are proactive in the sense that they try to prevent problems before they have a chance to occur. Leaders have to cultivate Cooperation spirit of working together to achieve strategic plan goals and create a healthy environment in which employees work side by side to achieve both personal and organizational objectives.

\section{Conclusions}

Based on the findings of the study the following conclusions are drawn:-

The study identified factors that had negatively affected the success of strategy implementation in teachers colleges which all originate from both within and outside the colleges. These were, resource unavailability, poor communication, fear of change, Lack of skills among the tutors and management in the formulation and implementation of the plan, leadership and laziness.

\section{Recommendations}

From the conclusions of this study, the following recommendations were made: The findings indicated the need for comprehensive in-service training for all college management and tutors to understand the formulation and implementation of the strategic plan. There is a need for the Ministry of Education Science and Technology, to review and harmonize existing policies on strategic planning in colleges. 
The study recommended that the Ministry of Education Science and Technology should emphasize the role of strategy execution with the view of improving the academic performance of their colleges. This was because the strategy execution had found to have a significant influence on academic performance. Also, the Ministry of education should create a mechanism where the Ministry's strategic plan is linked to teachers' college's strategic plans.

\section{References}

i. Abdel-Basset, M., Mohamed, M., \& Smarandache, F. (2018). An extension of neutrosophic AHP-SWOT analysis for strategic planning and decision-making. Symmetry, 10(4), 116.

ii. Alice, M. (2013). Factor affecting effectiveness of strategic plan in Non-governmental organization in Kenya. Jomo Kenyatta University of Agricultural and Technology.

iii. Anyieni, Abel G.; Areri., Damaris, K. (2016). Assessment of the Factors Influencing the Implementation of Strategic Plan in Secondary Schools in Kenya, Journal of Education and Practice, v7 n16 p1-8 2016

iv. Awino, Z. B., Njeru, W. G., \& Adwet, K. (2017). Strategy Implementation: Mckinsey's 7s Framework Configuration and Performance of Large Supermarkets in Nairobi, Kenya. Archives of Business Research, 5(6).

v. Brunsson, N., \& Olsen, J. P. (2018). The Reforming organization: making sense of administrative change. Routledge.

vi. Carter, N., Bryant-Lukosius, D., DiCenso, A., Blythe, J., \& Neville, A. J. (2014, September). The use of triangulation in qualitative research. In Oncology nursing forum (Vol. 41, No. 5).

vii. Chukwumah, Fides Okwukweka; Ezeugbor, Carol Obiagel (2015). Problems of Implementation of Strategic Plan for Secondary Schools' Improvement in Anambra State Educational Research and Reviews, v10 n10 p1384-1389

viii. Creswell (2013). Research Design Qualitative, Quantitative, And Mixed Method Approaches SAGE Publications

ix. Creswell, J. W., \& Miller, D. L. (2000). Determining validity in qualitative inquiry. Theory into Practice, 39(3), 124131.

x. Dominic, M. (2014) Factors Affecting the Implementation of Strategic Plan in Public Secondary Schools in Nyeri County, Kenya Jomo Kenyatta University of Agriculture \& Technology City square, Nairobi-Kenya.

xi. Elbanna, S., Andrews, R., \& Pollanen, R. (2016). Strategic planning and implementation success in public service organizations: Evidence from Canada. Public Management Review, 18(7), 1017-1042.

xii. Kaufman, B. E. (2016). The quest for cooperation and unity of interest in industry. In Industrial relations to human resources and beyond: The evolving process of employee relations management (pp. 127-158). Routledge.

xiii. Khan, R., Naseem, A., \& Masood, S. A. (2016). Effect of continuance commitment and organizational cynicism on employee satisfaction in engineering organizations. International journal of innovation, management and technology, 7(4), 141.

xiv. Kok, T. (2013) Adapting or adopting an instrument for your study, School of Educational Studies Universiti Sains Malaysia

xv. Lewis, L. (2019). Organizational change: Creating change through strategic communication. John Wiley \& Sons.

xvi. Mih, C., \& Mih, V. (2016). Fear of failure, disaffection and procrastination as mediators between controlled motivation and academic cheating. Cognition, Brain, Behavior, 20(2), 117.

xvii. MOEST (1018) Visit inspection Report from zonal chief Quality Assurance office.

xviii. MOEST (2018) Quality assurance reports from Lake zone, Eastern and Western zone.

xix. MOEST, (2017) Education program for Results (EPforR) Annual Report

xx. Mutisya, S. (2016). Influence of communication on strategy implementation among Pharmaceutical companies in Nairobi Kenya (Doctoral dissertation, United States International University-Africa).

xxi. $\quad$ Mwai, R. N., Namada, J. M., \& Kamau, J. N. (2018) conducted a research on Influence of Manager Personality on Strategy Implementation in Private Universities in Kenya. Journal of Organizational Psychology, 18(3).

xxii. Ndegwah, (2014) Factors Affecting the Implementation of Strategic Plan in Public Secondary Schools in Nyeri County, Kenya. Jomo Kenyatta University of Agriculture \& Technology

xxiii. Nunnally, J.C. and Bernstein, I.H. (1994) The Assessment of Reliability. Psychometric Theory, 3, 248-292.

xxiv. Nwachukwu, C. E., Chládková, H., \& Olatunji, F. (2018). The Relationship between Employee Commitment to Strategy Implementation and Employee Satisfaction. Trends Economics and Management, 12(31), 46-56.

xxv. Ochola (2016) The effect of management skills in the implementation of strategy by smes in the pharmaceutical industry in Nairobi city county, Kenya

xxvi. Odero, J. A. (2016). Communication as a Factor Affecting Effective Strategy Implementation in the Banking Industry in Kakamega County, Kenya. International Journal of Management Research and Reviews, 6(7), 950.

xxvii. Odero, J. A., \& Mutua, M. S. (2016). Influence of Organizational Culture on the Implementation of Strategic Plan among Commercial Banks in Kenya: A Case Study of Co-Operative Bank of Kenya. International Journal of Multidisciplinary and Current Research, 4.

xxviii. Strategic planning has its origin in warfare (Wolf, C., \& Floyd, S. W. (2017). Strategic planning research: Toward a theory-driven agenda. Journal of Management, 43(6), 1754-1788.

xxix. Sull, D., Homkes, R., \& Sull, C. (2015). Why strategy execution unravels-and what to do about it. Harvard Business Review, 93(3), 57-66.

xxx. Wood, S. A. (2017). Atychiphobia, Failure, Genre, and Vulnerability Inside and Outside the Writing Classroom. 